\title{
Current Understanding of Narcolepsy 1 and its Comorbidities: What Clinicians Need to Know
}

\author{
Lois E. Krahn • Phyllis C. Zee $\cdot$ Michael J. Thorpy
}

Received: September 1, 2021 / Accepted: November 9, 2021 / Published online: December 11, 2021

(c) The Author(s) 2021

\begin{abstract}
Narcolepsy is a chronic neurologic disorder associated with the dysregulation of the sleep-wake cycle that often leads to a decreased quality of life and results in a considerable health burden. There is often a delay to diagnosis of narcolepsy, mainly due to the lack of recognition of this disorder. One of the main factors hindering the diagnosis of narcolepsy is the association of comorbidities, which include other sleep disorders, psychiatric disorders,
\end{abstract}

L. E. Krahn

Department of Psychiatry and Psychology, Mayo

Clinic College of Medicine, Phoenix, AZ, USA

L. E. Krahn

Division of Pulmonary Medicine, Mayo Clinic

College of Medicine, Phoenix, AZ, USA

L. E. Krahn

Center of the Science of Healthcare Delivery, Mayo

Clinic College of Medicine, Phoenix, AZ, USA

P. C. Zee

Center for Circadian and Sleep Medicine,

Northwestern University, Chicago, IL, USA

P. C. Zee

Department of Neurology, Sleep Medicine,

Northwestern University, Chicago, IL, USA

M. J. Thorpy ( $\varangle)$

Montefiore Medical Center, Albert Einstein College

of Medicine, 111 East 210th Street, Bronx, NY

10467, USA

e-mail: michael.thorpy@einsteinmed.org cardiovascular disorders, and metabolic disorders. The signs and symptoms of these comorbidities often overlap with those of narcolepsy, and some of the medications used for their treatment may obscure the symptoms of narcolepsy, leading to a delay in diagnosis. This review is targeted to clinicians unaccustomed to working with sleep disorders and aims to increase recognition and improve the management of narcolepsy.

Keywords: Cataplexy;

Comorbidities; Diagnostic delay; Excessive daytime sleepiness; Hypersomnolence; Narcolepsy; Orexin; Rapid eye movement; Sleep disorders 


\section{Key Summary Points}

Narcolepsy is a neurological disorder associated with loss of orexin (hypocretin)-producing neurons in the lateral hypothalamus of the brain, possibly due to an autoimmune response.

Orexin neurons project to areas of the brain important for sleep-wake cycle, as well as alertness, attention, mood modulation, and executive function.

Symptoms include excessive daytime sleepiness, abnormal rapid eye movement (REM) sleep phenomena including cataplexy, and disrupted nighttime sleep.

Diagnosis of narcolepsy can be complicated by a variety of comorbidities that lead to misdiagnoses, delay in diagnosis, and complicate management.

Patients with narcolepsy require a comprehensive evaluation that assesses both associated symptoms and coexisting conditions.

Treatment options for narcolepsy are primarily pharmacologic and will often depend upon the severity of symptoms, recognition of patient lifestyle, and coexisting medical and psychiatric comorbidities.

\section{INTRODUCTION}

Narcolepsy is a chronic neurologic disorder characterized by excessive daytime sleepiness (EDS), disruption of rapid eye movement (REM), sleep regulation, and disturbed nocturnal sleep; it is a $24 \mathrm{~h}$ of the day disorder. Symptoms characteristic of disrupted REM sleep can include cataplexy, sleep paralysis, sleep-related hallucinations, and frequent vivid dreams [1-5]. Although narcolepsy is associated with major impairments in function and quality of life, it is often under-recognized, which leads to a delay in diagnosis of 9-22 years, ultimately increasing the disease burden $[4,6]$. One of the main reasons for the delay between the onset of narcolepsy symptoms and the time of diagnosis is the overlap of symptoms with other more common disorders, such as insomnia, obstructive sleep apnea, attention-deficit hyperactivity disorder (ADHD), depression, anxiety and mood disorders, and other psychiatric conditions [6]. In addition, the high presence of comorbidities in patients with narcolepsy may delay recognition and, consequently, treatment of this disorder [7].

Narcolepsy symptoms can significantly affect patients' lives, impairing their ability to function at school and work, as well as negatively impacting their household responsibilities, relationships with friends and family, mood, and self-esteem $[8,9]$. Even after diagnosis and treatment, the impact of narcolepsy is high, with patients experiencing lower quality of life, reduced productivity, and higher utilization of healthcare resources than individuals without narcolepsy [10, 11].

In order to address the consequences and clinical burden associated with the lack of recognition of narcolepsy, there is a need for a better understanding of the symptoms, clinical spectrum, comorbidities, pathophysiology, and treatment options. Thus, the aim of this review is to describe the current understanding of narcolepsy and discuss the consideration of comorbidities in clinical strategies for the diagnosis and management of patients with this disorder.

This article is based on previously conducted studies and does not contain any new studies with human participants or animals performed by any of the authors.

\section{METHODS}

A literature search of the PubMed database was conducted for English language articles (research articles, reviews, systematic reviews, meta-analyses) published between January 1, 2002 and September 20, 2021. Search terms included narcolepsy; diagnosis; cataplexy; 
pathophysiology, orexin; autoimmunity; cytotoxic T cells; narcolepsy scales; actigraphic assessment; cognitive impairments; patient-reported measures; comorbidities; healthcare utilization; costs. This article is based on previously conducted studies and does not contain any new studies with human participants or animals performed by any of the authors.

\section{DEFINITION AND CLINICAL SYMPTOMATOLOGY OF NARCOLEPSY}

Narcolepsy is a chronic and often disabling neurologic sleep disorder that affects patients' quality of life and is primarily defined by EDS and altered REM sleep [12, 13]. There are two types of narcolepsy, narcolepsy type 1 (NT1) and narcolepsy type 2 (NT2). NT1 is characterized by cataplexy and, when measured, orexin (also known as hypocretin) deficiency. NT2 is less well understood, does not present with cataplexy, and exhibits normal levels of orexin (if measured) [14].

The cardinal sign of narcolepsy is EDS. EDS is characterized by a constant background of baseline sleepiness, tiredness or fatigue together with lapses into sleep throughout the day that can be voluntary (naps) or involuntary (sleep attacks) [1]. Patients with narcolepsy often wake up feeling refreshed after naps (unlike patients with obstructive sleep apnea, idiopathic hypersomnia, and sleep deprivation) but may experience sleep inertia after waking, feel sleepy again soon after waking, and have trouble staying awake throughout the day, particularly during sedentary periods, leading to persistent daytime sleepiness $[4,15,16]$.

Disrupted nighttime sleep (DNS) is also a common symptom in patients with narcolepsy and is characterized by difficulties in sleep continuity, such as frequent arousals, an inability to stay asleep, and poor sleep quality, although patients usually fall asleep quickly [17]. Despite DNS having a high prevalence in people with narcolepsy, it can also be secondary to a comorbid sleep disorder, such as obstructive sleep apnea [17]. Narcolepsy-related DNS differs from insomnia-related DNS in that patients with narcolepsy do not usually have difficulty falling asleep, as do patients with insomnia [17]. Hence, narcolepsy is characterized by short initial sleep latency, whereas the sleep latency in patients with insomnia is usually long [17].

These disturbed patterns of sleep described in patients with narcolepsy have been partly attributed to the dysregulation of REM sleep [18]. REM sleep typically occurs exclusively during nighttime sleep, but patients with narcolepsy experience REM intrusions in the daytime and during daytime naps [4]. When REM occurs during daytime sleep, patients may experience vivid dreams during naps and can also experience auditory or visual hallucinations, as well as episodes of sleep paralysis [4]. At night, REM sleep dysregulation may manifest as frequent, vivid, and frightening dreams, as well as REM sleep behavior disorder (RBD; e.g., the acting out of dreams during sleep, particularly in children) $[1,3,4,19]$. A major manifestation of the abnormal intrusion of REM into wakefulness is cataplexy $[4,5,20]$.

Cataplexy, the pathognomonic symptom of NT1, is the sudden and transient loss of muscle tone that is a partial manifestation of REM sleep during wakefulness, resulting in complete or partial paralysis, and is triggered by strong emotions, including laughter, elation, surprise, or anger $[4,5]$. Consequently, patients may stop participating in activities they have previously enjoyed in order to avoid experiencing this symptom [21]. Cataplexy is usually of short duration (seconds-minutes) and, although it can affect the whole body, it can be partial or localized (affecting limbs or head and neck) in most patients [4, 7, 21]. Of note, narcolepsy symptoms often initially manifest differentially in pediatric versus adult patients. For example, cataplexy symptoms in children may include faint and unusual facial expressions or choreiclike movements, which are not observed in adult patients with narcolepsy and cataplexy. This can complicate the diagnosis of narcolepsy in children [9].

In summary, although narcolepsy symptoms may present in childhood or adolescence in most patients, not all symptoms are present at 
the time of diagnosis and may differ between patients $[4,13,17]$. Nor are these symptoms, except for cataplexy, exclusive to narcolepsy. As a result, to improve recognition and ensure appropriate treatment, narcolepsy should be considered a possibility in all patients with EDS $[7,22]$.

\section{PATHOPHYSIOLOGY OF NARCOLEPSY}

The discovery approximately 20 years ago linking selective loss of orexin-producing neurons in the lateral hypothalamus with narcolepsy represented a major advance in sleep research in general, and provided an important clue to the underlying pathogenesis of NT1 [23, 24]. Orexin (also known as hypocretin) is an important regulator of sleep/wake behavior, and animal and human studies point to loss of orexin-producing neurons as the major underlying cause of NT1 [24-29].

Selective loss of orexin-producing neurons in the hypothalamus results in decreased levels of orexin in the cerebrospinal fluid (CSF) in genetically susceptible individuals (Fig. 1)

a Mechanisms of sleepiness in narcolepsy

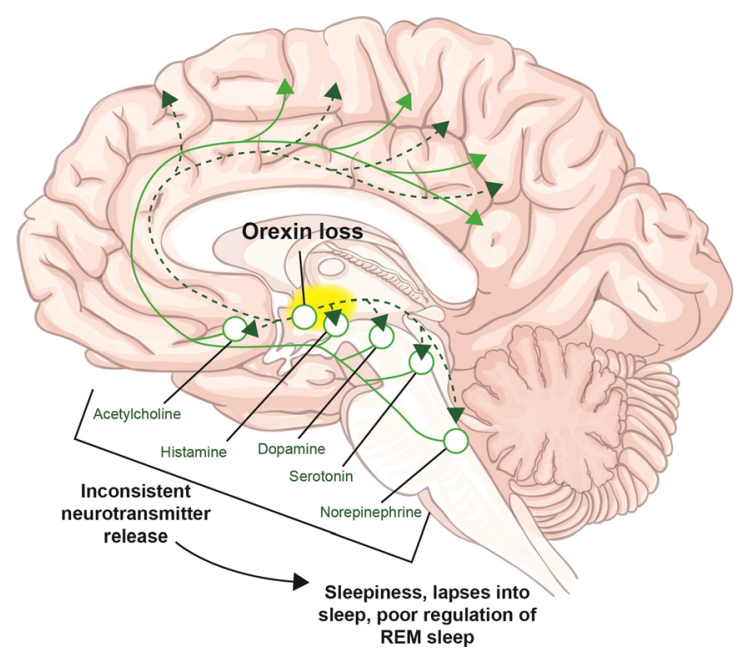

Fig. 1 The orexin pathways that a promote and maintain wakefulness, and $\mathbf{b}$ suppress REM sleep as well as maintain muscle tone during wakeful periods. Loss of orexin can
$[23,24]$. CSF orexin levels are low or absent $(<110 \mathrm{pg} / \mathrm{ml})$ in patients with NT1 but are within the normal range in patients with NT2 [24].

Orexin neurons project to many brain regions, from the cortex to the spinal cord and innervate areas that not only regulate wakefulness and REM sleep (Fig. 1), but also increase reward-seeking behavior, learning, and locomotion, as well as having immunologic, autonomic, and metabolic effects [24]. In addition, orexin neurons receive signals from brain areas that regulate fear, anxiety, visceral sensations, and cardiovascular autonomic tone $[24,30]$. These neuronal circuits may help explain some of the comorbidities linked with NT1.

The loss of orexin-producing neurons characteristic of NT1 has been hypothesized to be caused by an autoimmune mechanism [24, 31]. This is supported by the strong genetic association of narcolepsy with human leukocyte antigen (HLA) alleles and with polymorphisms in the T cell receptor alpha locus [24, 32, 33]. Genome-wide association studies have shown that almost all patients with NT1 who have a significant decrease in CSF orexin levels carry the $H L A D Q B 1{ }^{*} 06: 02$ allele $[24,32]$. This allele

\section{b Mechanisms of cataplexy in narcolepsy}

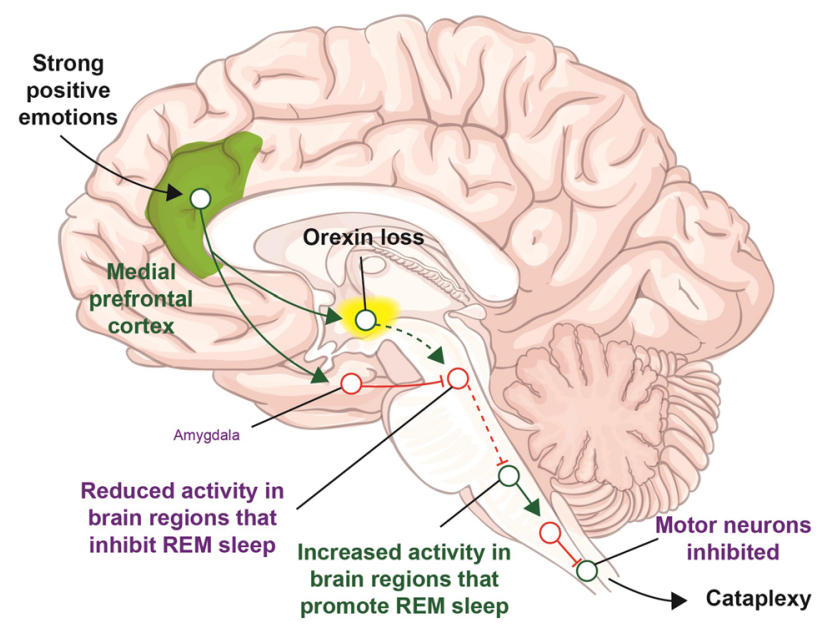

disrupt these pathways, leading to sleepiness and cataplexy, respectively. REM rapid eye movement. Adapted with permission from Scammell [4] 
encodes major histocompatibility complex proteins that hypothetically may present orexin peptides to T cells, which recognize the orexin peptides as foreign, in turn activating their receptors and mediating autoimmune activity that leads to the depletion of orexin-producing neurons in the hypothalamus [34, 35]. Differences in the immune responses in patients with NT1 and HLADQB1*06:02-matched healthy controls showed immune activation in $\mathrm{CD} 4^{+}$ and $\mathrm{CD}^{+} \mathrm{T}$ cells, as well as elevated levels of $B$ cell supporting cytokines in NT1 [36]. In addition, T cells from patients with NT1 have demonstrated increased production of the proinflammatory cytokines interleukin-2 (IL-2) and tumor necrosis factor (TNF). However, even though the results indicate that inflammatory processes are involved in the pathogenesis of NT1, they cannot distinguish whether these heightened inflammatory responses are primary to an autoimmune process or secondary to orexin deficiency [36].

Autoreactive memory $\mathrm{CD}^{+}$and-in some cases- $\mathrm{CD}^{+} \mathrm{T}$ cells have been shown to target self-antigens expressed by neurons that produce hypocretin HCRT [37]. However, a recent study found that autoreactive $\mathrm{CD} 4^{+} \mathrm{T}$ cells targeting epitopes from the orexin precursor were either not present or present in a frequency less than 1:10,000 among $\mathrm{CD}^{+}{ }^{+}$T cells from patients with NT1 [38].

In addition, two other recent studies have provided some support for the proposed autoimmune mechanism for NT1 by finding that a certain level of $\mathrm{CD}^{+} \mathrm{T}$ cell reactivity combined with $H L A D Q B 1{ }^{*} 06: 02$ expression may predispose for NT1 development [31, 39]. These findings suggest the possibility that autoimmune cell detection in the blood could potentially aid in the diagnosis of narcolepsy [37]. Additional studies are needed to better explore the proposed autoimmune hypothesis of NT1.

Studies that showed a surge in NT1 in children following the influenza (H1N1) vaccination campaign in Europe with Pandemrix (GlaxoSmithKline) between 2009 and 2010 have also been used to support the autoimmune basis for orexin depletion. All immunized carriers of the $H L A D Q B 1{ }^{*} 06: 02$ allele who developed NT1 did so weeks to months after the vaccination [24]. Although the exact mechanism by which this may have happened is still unknown, there are two prevailing hypotheses: (1) the molecular mimicry to flu antigens hypothesis [24, 39] and (2) the bystander activation of autoreactive $\mathrm{T}$ cells hypothesis, which involves another infection triggering an autoimmune response that may indirectly damage close-by orexin cells [34, 35]. In support of the latter hypothesis, a retrospective, case-control study indicated that $65 \%$ of patients with recent narcolepsy onset had antistreptococcal antibodies, suggesting that Streptococcus pyogenes infections may trigger an autoimmune response leading to the destruction of orexin cells in narcolepsy [40]. This might also explain the results obtained after an H1N1 vaccination campaign in China, where even non-vaccinated people developed NT1 during the winter of 2009-2010, suggesting that narcolepsy could also be triggered by seasonal upper airway infections [41].

While $H L A D Q B I^{*} 06: 02$ is present in almost all patients with NT1, it is present in only $30-50 \%$ of patients with NT2 [42]. Moreover, this allele is not exclusive to patients diagnosed with narcolepsy; about $20 \%$ of the European population also carry $H L A D Q B 1{ }^{*} 06: 02$ on one chromosome [32]. Polymorphisms in other genes involved in the immune response are also associated with a genetic predisposition to develop narcolepsy, including P2RY11, EIF3G, CTSH, and TNFSF4 $[43,44]$.

\section{DIAGNOSIS OF NARCOLEPSY AND SYMPTOM SEVERITY}

Early diagnosis of narcolepsy is vital to decrease the burden associated with this disease; However, as a result of the challenges in differentiating and identifying narcolepsy symptoms, it is often underdiagnosed and confounded by other mental and neurologic conditions, leading to a poor patient quality of life and performance (e.g., productivity) [6]. In addition, the presence of psychiatric comorbidities represents a significant challenge that can lead to a masking of narcolepsy symptoms and, thus, a delay in its 
Table 1 ICSD-3 and DSM-5 diagnostic criteria for narcolepsy [2, 12, 47]

\section{ICSD-3 [47]}

NT1: both criteria $A$ and $B$ must be met

A. The patient has daily periods of irrepressible need to sleep or daytime lapses into sleep occurring for at least 3 months

B. The presence of one (or both) of the following:

1. Cataplexy and a mean sleep latency of $\leq 8 \mathrm{~min}$ and $\geq 2$ SOREMPs on an MSLT performed according to standard techniques. A SOREMP (within $15 \mathrm{~min}$ of sleep onset) on the preceding nocturnal PSG may replace one of the SOREMPs on the MSLT

2. CSF hypocretin-1 concentration, measured by immunoreactivity, is either less than or equal to $110 \mathrm{pg} / \mathrm{mL}$ or less than one-third of mean values obtained in normal subjects with the same standardized assay

NT2: criteria A-E must be met

A. The patient has daily periods of irrepressible need to sleep or daytime lapses into sleep occurring for at least 3 months

B. A mean sleep latency of $\leq 8 \mathrm{~min}$ and $\geq 2$ SOREMPs are found on an MSLT performed according to standard techniques. A SOREMP (within 15 min of sleep onset) on the preceding nocturnal PSG may replace one of the SOREMPs on the MSLT

C. Cataplexy is absent

D. Either CSF hypocretin-1 concentration has not been measured or CSF hypocretin-1 concentration measured by immunoreactivity is either greater than $110 \mathrm{pg} / \mathrm{mL}$ or greater than one-third of mean values obtained in normal subjects with the same standardized assay
DSM-5 [12]

A. Recurrent periods of an irrepressible need to sleep, lapsing into sleep, or napping occurring within the same day. These must have been occurring at least three times per week over the past 3 months

B. The presence of at least one of the following:

1. Episodes of cataplexy, defined as either (a) or (b), occurring at least a few times per month:

(a) In individuals with long-standing disease, brief (seconds to minutes) episodes of sudden bilateral loss of muscle tone with maintained consciousness that are precipitated by laughter or joking

(b) In children or individuals within 6 months of onset, spontaneous grimaces or jaw-opening episodes with tongue thrusting or a global hypotonia, without any obvious emotional triggers

2. Hypocretin deficiency, as measured using CSF hypocretin-1 immunoreactivity values (less than or equal to one-third of values obtained in healthy subjects tested using the same assay, or less than or equal to $110 \mathrm{pg} / \mathrm{mL}$ ). Low CSF levels of hypocretin-1 must not be observed in the context of acute brain injury, inflammation, or infection

3. Nocturnal sleep PSG showing REM sleep latency $\leq 15 \mathrm{~min}$, or an MSLT showing a mean sleep latency $\leq 8 \mathrm{~min}$ and $\geq 2$ SOREMPs 
Table 1 continued

ICSD-3 [47]

DSM-5 [12]

E. The hypersomnolence and/or MSLT findings are not

better explained by other causes, such as insufficient sleep,

obstructive sleep apnea, delayed sleep phase disorder, or

the effect of medication or substances or their withdrawal

$C S F$ cerebrospinal fluid, DSM-5 Diagnostic and Statistical Manual of Mental Disorders Fifth Edition, ICSD-3 International Classification of Sleep Disorders Third Edition, $M S L T$ multiple sleep latency test, $N T 1$ narcolepsy type 1, NT2 narcolepsy type 2, $P S G$ polysomnography, REM rapid eye movement, SOREMP sleep-onset rapid eye movement period

diagnosis $[6,45]$. Children may also experience delayed diagnosis as their symptomatology often differs from that in adults, and data regarding diagnosis in the pediatric population are scarce $[14,46]$.

The diagnostic criteria are defined in the International Classification of Sleep Disorders, third edition (ICSD-3) [47] and in the Diagnostic and Statistical Manual of Mental Disorders, fifth edition (DSM-5) (Table 1) [12]. These diagnostic criteria include symptom recognition and physiologic assessment of nocturnal sleep quality, daytime sleepiness, and the presence of REM sleep during daytime naps using mean sleep latency determined by the multiple sleep latency test (MSLT) in conjunction with nocturnal sleep polysomnography (PSG). The MSLT must be conducted under ideal conditions to ensure that it is not affected by prior sleep deprivation or concomitant medications $[6,48]$. Chronic sleep deprivation is a possible confounding factor of MSLT results. In addition to the sleep studies, the ICSD-3 and DSM-5 recognize the presence of biomarkers, such as hypocretin-1 levels in CSF, as diagnostic criteria in narcolepsy $[2,12,13]$. The measurement of CSF orexin levels is usually only conducted in cases of atypical or ambiguous cataplexy as it requires a spinal tap and the assay is not readily available to most sleep clinicians [13]. The diagnostic criteria for another disorder of primary central hypersomnolence, idiopathic hypersomnia, are similar to those for narcolepsy but include fewer than two sleep-onset REM periods (SOREMPs), whereas at least two are required for a diagnosis of narcolepsy $[2,12,13]$.

To ensure accurate and rapid diagnosis, physicians should suspect narcolepsy in any patient with EDS and investigate the presence of other symptoms of narcolepsy, paying careful attention to the patient's sleep habits history, particularly abnormal REM sleep phenomena, as well as current and past medical disorders, work patterns (e.g., shift work), and medications (including over-the-counter agents), to help discriminate between conditions with a similar presentation $[6,13]$.

Actigraphic assessment of sleep/wake behavior may be used to assist in differentiating patients with NT1 from those with a long nocturnal sleep period associated with idiopathic hypersomnia [49-51].

A variety of subjective scales are available for clinicians to use when assessing symptoms and their severity and include the Epworth Sleepiness Scale (ESS), the Ullanlinna Narcolepsy Scale, Swiss Narcolepsy Scale, the Narcolepsy Symptom Assessment Questionnaire, and the Narcolepsy Severity Scale [52, 53]. Modifications of the ESS-the Epworth Sleepiness Scale for Children and Adolescents (ESS-CHAD) and the Pediatric Narcolepsy Severity Scale (NSS-P)—are specifically designed for use in children and adolescents [54, 55]. 


\section{COGNITIVE IMPAIRMENTS ASSOCIATED WITH NARCOLEPSY}

A recent 2021 systematic review discussed various forms of cognitive dysfunction in narcolepsy and other central disorders of hypersomnolence [56]. Forty-three studies that assessed cognitive function in patients with NT1 were included in the review. Patients with NT1 exhibited cognitive impairment or suboptimal performance relative to healthy controls and/or patients with NT2 in attention (alertness, selective attention, divided attention, and sustained attention and vigilance), memory (declarative memory, procedural memory, and learning), some evaluations of executive function (specifically flexibility, but generally not inhibition, planning, set-shifting, reasoning, or planning), and higher-order cognitive functions (decision-making and emotional processing, but generally not creativity or fluency) [56].

Attention impairments associated narcolepsy were explored by Filardi et al., who used the attention network test (ANT) in patients with NT1 and NT2 and healthy controls to explore the impact of orexin deficit on alerting (alertness) and orienting and executive control [57]. Questionnaires were also used to assess attention-deficit hyperactivity disorder (ADHD), obsessive-compulsive disorder, anxiety, and depressive symptoms in the three groups, and their impact alerting, orienting, and control networks. The results showed that patients with NT1 and patients NT2 both had slower reaction times compared with controls. However, patients with NT1 also exhibited an impairment in the alerting network relative to NT2 and healthy controls. In addition, patients with NT1 scored higher on the ADHD hyperactive domain and had higher depressive symptoms than the other the two groups, with a correlation between ADHD and depressive symptoms in these patients. The results indicate a selective impairment of the alerting network in orexin-deficient (NT1) patients, i.e., that orexin is important for alertness [57].

Other studies have demonstrated deficiencies in selective attention, as well as other cognitive functions, in patients with NT1 compared with controls. Schneider et al. examined alertness, selective attention, and sleepiness in patients with NT1 or obstructive sleep apnea, or insomnia, and controls using a critical flicker fusion test (a measure of optical fusion threshold and alertness), a paper-andpencil visual line tracking test (selective attention measure), and a visual analog scale for tiredness/sleepiness [58]. Various cognitive tests showed decrements in alertness and selective attention in untreated patients with NT1, insomniacs, and sleep apnea versus controls. Of note, patients with NT1 showed the worst overall performance. Another study used the Psychomotor Vigilance Task (PVT) - an assay of sustained attention that is highly sensitive to the effects of sleep loss-to compare patients with NT1 with others with insufficient sleep syndrome (ISS), hypersomnia, or controls [59]. Several PVT outcomes were analyzed, with patients with NT1 showing slower and more variable reaction times and increased omission error relative to patients with ISS or controls.

\section{CONFOUNDING FACTORS IN THE DIAGNOSIS OF NARCOLEPSY}

Narcolepsy can be difficult to diagnose accurately from clinical signs and symptoms given that the onset can be gradual; therefore, patients may not be diagnosed until their lives are seriously affected (e.g., by reduced work productivity or a car accident) [4]. In addition, as mentioned earlier, not all symptoms are simultaneously present or accurately identified at the time of diagnosis [13]. For example, patients with narcolepsy often describe sleepiness as "fatigue" or "tiredness" which may mislead the clinician $[45,60]$. Furthermore, cataplexy may be absent or can develop some years after the initial onset of daytime sleepiness [14], or daytime sleepiness can be misdiagnosed as a different sleep disorder (e.g., sleep apnea syndrome, sleep deprivation) $[4,61]$. Even when present, cataplexy may be misdiagnosed as a different neurologic condition (e.g., epilepsy, drop attack) or may be subtle, 
manifesting as mild facial, head, or limb weakness [20].

The factors that confound the diagnosis of narcolepsy tend to be even more challenging in children, as they may not be able to describe the symptoms they are experiencing, and they or their caregivers may not recognize EDS $[8,62]$. Children with narcolepsy are often misdiagnosed with ADHD when they experience restlessness, irritability, attention problems, and/or emotional lability because of their EDS $[8,9]$, which may also lead to delays in the recognition of sleepiness and cataplexy. Also, the manifestations of narcolepsy may be different in children than in adults and may differ between children with prepubertal versus adolescent onset [9]. For example, sleep attacks tend to occur more often and last longer in children with prepubertal onset than in those with adolescent onset [9]. Cataplexy in adults is usually precipitated by positive emotions and, to a lesser extent, by negative emotions, but in children the triggers may be more varied $[20,54]$. For example, laughter triggers cataplexy at least some of the time in children regardless of age of onset, but they may also experience cataplexy in response to anger, excitement, and fear [54]. In children, cataplexy can manifest as atonia (in which they drop objects or stumble, or develop ptosis or jaw slackening) or as hyperkinesis (marked by facial twitches or grimacing) [8, 20]. Consequently, cataplexy in children may be misdiagnosed as another neuropsychiatric disorder [8], potentially resulting in the use of a pharmacologic treatment that could mask symptoms or even aggravate cataplexy in narcolepsy [46, 61].

Narcolepsy needs to be distinguished from other disorders characterized by EDS, such as sleep deprivation, psychiatric disorders, and other medical and neurologic disorders (Table 2) [2, 4, 45, 63], since these disorders have symptoms that overlap with the typical symptomatology in narcolepsy, and their treatment may obscure and complicate narcolepsy diagnosis $[3,45]$. For instance, a druginduced confounding effect has been described in a case study of a heavy smoker whose nicotine intake suppressed her cataplexy and sleepiness, delaying narcolepsy diagnosis until her mid-70s [64]. Another case study described a 40-year delay to diagnosis in a patient with narcolepsy and ADHD, probably due in part to the masking effect of ADHD treatment in improving attention [65]. Hence, further effort should be made to understand the relationship between narcolepsy, its comorbidities, symptom overlap with other disorders, and the effect of their treatment on disease prognosis and quality of life of patients with narcolepsy.

Narcolepsy in adults and children has been related to a significant number of comorbidities, including psychiatric, cardiometabolic, and other sleep disorders that may obscure the symptoms of narcolepsy, hinder its diagnosis, and complicate its management (Table 3) $[54,55]$.

\section{Comorbidities}

\section{Sleep Disorders}

In a retrospective analysis of comorbidities in patients with narcolepsy in the USA, adults with narcolepsy had a significantly higher prevalence of sleep apnea at diagnosis compared with individuals without narcolepsy (excess prevalence of $45.6 \%$ ) [22]. Moreover, the incidence of sleep comorbidities is not exclusive to adults; a retrospective cross-sectional study demonstrated that pediatric patients with narcolepsy also had a significantly higher prevalence of other sleep disorders, such as insomnia, sleeprelated movement disorders, sleep apnea, and circadian rhythm sleep-wake disorders compared with children without narcolepsy [62]. Consequently, physicians may recognize the comorbid disorder but miss the underlying narcolepsy in both adults and children $[4,20,62]$.

\section{Psychiatric Disorders}

Several studies have demonstrated an increased prevalence of mood disorders, depression, and anxiety among patients with narcolepsy $[22,66]$. A meta-analysis of 31 studies (including 6 studies in children and adolescents) found that $32 \%$ of patients with narcolepsy had comorbid depression [67], and a survey study found that patients with narcolepsy and 
Table 2 Conditions to consider in the differential diagnosis of narcolepsy $[4,63]$

\begin{tabular}{|c|c|}
\hline Disorder type & Specific disorder \\
\hline \multirow[t]{7}{*}{ Sleep disorders } & Idiopathic hypersomnia \\
\hline & Insufficient sleep/poor sleep hygiene \\
\hline & Obstructive sleep apnea \\
\hline & REM sleep behavior disorder \\
\hline & Delayed sleep phase disorder \\
\hline & Shift-work sleep disorder \\
\hline & Insomnia \\
\hline \multirow[t]{3}{*}{ Psychiatric disorders } & Depression \\
\hline & Anxiety \\
\hline & Psychosis (if sleep-related hallucinations are present) \\
\hline \multirow[t]{7}{*}{ Neurologic disorders } & Autism \\
\hline & Benign childhood epilepsy \\
\hline & Front lobe epilepsy \\
\hline & Periodic limb movement disorder \\
\hline & Transient global amnesia \\
\hline & Absence seizures \\
\hline & Complex partial seizures \\
\hline \multirow[t]{4}{*}{ Other medical disorders } & Use of sedating medications \\
\hline & Syncope \\
\hline & Prader-Willi syndrome \\
\hline & Niemann-Pick disease type $\mathrm{C}$ \\
\hline
\end{tabular}

$R E M$ rapid eye movement

comorbid depression had worse quality of life than patients with narcolepsy and without comorbid depression [67]. EDS may be ascribed to depression, especially an atypical depression, or it may be masked by the medications taken for depression, without further investigation to determine a potential narcolepsy diagnosis $[4,20,45,46]$.

\section{Cardiovascular Disorders}

The aforementioned retrospective analysis of comorbidities in patients with narcolepsy in the USA also showed that there is a higher prevalence of cardiovascular system disorders $(16.6 \%)$ in these patients [22]. These data are in line with another US study that used data from the Rochester Epidemiology Project database, which found that patients with narcolepsy were significantly more likely to have obesity, hypertension, and hyperlipidemia at diagnosis compared with individuals without narcolepsy [66].

The relationship between cardiovascular disease and narcolepsy is possibly related to the effect of the orexin system on autonomic cardiovascular function. Studies in orexin- 
Table 3 Patients within dataset of specific conditions previously associated with narcolepsy: control subjects versus subjects with narcolepsy [22]

\begin{tabular}{|c|c|c|c|c|c|}
\hline \multirow[t]{2}{*}{ CCS category or ICD-9 diagnosis code } & \multicolumn{2}{|c|}{$\begin{array}{l}\text { Patients with } \\
\text { comorbidity, } n \text { (\%) }\end{array}$} & \multirow[t]{2}{*}{$\begin{array}{l}\text { Excess } \\
\text { prevalence }\end{array}$} & \multirow[t]{2}{*}{$p$ value $^{\mathrm{a}}$} & \multirow[t]{2}{*}{$\begin{array}{l}\text { Odds ratio }^{b} \\
(95 \% \mathrm{CI})\end{array}$} \\
\hline & $\begin{array}{l}\text { Control } \\
N=46,559\end{array}$ & $\begin{array}{l}\text { Narcolepsy } \\
N=9312\end{array}$ & & & \\
\hline Anxiety disorders (651) & $5554(11.9)$ & $2333(25.1)$ & $13.2 \%$ & $<0.0001$ & $2.5(2.4,2.7)$ \\
\hline Diabetes $(49,50)$ & $8835(19.0)$ & $2635(28.3)$ & $9.3 \%$ & $<0.0001$ & $1.8(1.7,1.8)$ \\
\hline Headache/migraine (84) & $8424(18.1)$ & $3548(28.3)$ & $20 \%$ & $<0.0001$ & $2.9(2.8,3.1)$ \\
\hline Mood disorders (657) & $6407(13.8)$ & $3525(37.9)$ & $24.1 \%$ & $<0.0001$ & $4.0(3.8,4.2)$ \\
\hline Obesity (3.11.2) & $3933(8.4)$ & $1609(17.3)$ & $8.8 \%$ & $<0.0001$ & $2.3(2.2,2.5)$ \\
\hline Periodic limb movement disorder (327.51) & $2675(5.8)$ & $369(4.0)$ & $3.7 \%$ & $<0.0001$ & $14.8(12,18.1)$ \\
\hline $\begin{array}{l}\text { Sleep apnea }(327.20,327.21,327.23,327.27 \text {, } \\
\text { and } 3327.29)\end{array}$ & $2675(5.8)$ & $4787(51.4)$ & $45.6 \%$ & $<0.0001$ & $18.7(17.5,20.0)$ \\
\hline REM behavior disorder (327.42) & $5(0)$ & $44(0.5)$ & $0.5 \%$ & $<0.0001$ & $44(17.4,111)$ \\
\hline Restless leg syndrome (333.94) & $307(0.7)$ & $517(5.6)$ & $4.9 \%$ & $<0.0001$ & $8.9(7.7,10.3)$ \\
\hline
\end{tabular}

Reproduced with permission from Black et al. [22]

CCS Clinical Classification Software, REM rapid eye movement

${ }^{a}$ Conditional chi-squared test; accounts for matching

${ }^{\mathrm{b}}$ Odds ratios interpreted as narcolepsy versus control

knockout mice and in patients with NT1 found that heart rate was higher than normal during sleep time in orexin-knockout mice compared with wild-type mice and in most patients with NT1 compared with individuals without NT1. Further, in patients with NT1, there was a blunted fall in the arterial blood pressure from wakefulness to sleep compared with individuals without NT1 [30]. This dysregulation of blood pressure during the sleep-wake cycle was hypothesized to be due to low orexin levels, resulting in dysregulation of the orexin-mediated sympathoexcitatory signals that modulate autonomic cardiovascular activity during sleep, and particularly during wakefulness before sleep $[30,68]$.

\section{Metabolic Disorders}

Orexin neurons participate in the regulation of metabolism, including appetite, energy expenditure, and autonomic regulation [69]; consequently, orexin deficiency in narcolepsy increases the risk for metabolic comorbidities [70]. Patients with narcolepsy often gain weight, and the body mass index (BMI) of adults in this group is approximately $15 \%$ higher than the average BMI [4]. This has been attributed to orexin-mediated food-seeking behavior [70], a lower metabolic rate in orexin-deficient individuals [71], and the effect of the orexin system on brown adipose tissue functionality, which could be partly responsible for the impaired energy homeostasis, potentially resulting in increased adiposity and weight gain in patients with NT1 [71]. Compared with individuals without narcolepsy, patients with narcolepsy have a higher prevalence of diabetes (by 9.3\%) and obesity (by 8.8\%) [22].

Weight gain, obesity, and precocious puberty are more common in children with narcolepsy compared with children without narcolepsy [9]; therefore, children with narcolepsy may benefit from a referral to an endocrinologist. Weight gain and obesity could 
worsen other comorbid disorders (like diabetes) and mask narcolepsy symptoms, resulting in delays in the diagnosis of narcolepsy $[3,6,46]$.

\section{TREATMENT OPTIONS}

The major goals of treatment for narcolepsy are to alleviate the main symptoms (such as daytime sleepiness, cataplexy, and other abnormal REM sleep phenomena) and improve nocturnal sleep, so that patients can function as normally as possible in their day-to-day lives [72]. Although there are both pharmacologic and non-pharmacologic approaches to managing narcolepsy, most patients require pharmacological therapies. Non-pharmacological therapies include scheduled naps, sleep hygiene, and the avoidance of emotional situations that might precipitate cataplexy [73].

Before choosing a specific pharmacologic strategy for each patient, clinicians should consider lifestyle changes for their patients $[46,74]$, including maintaining a regular sleep schedule and sleep hygiene, planned naps, limiting intake of sweets/carbohydrates or alcohol, adding relaxation techniques and physical activity to their routine, and providing education and support to help patients, guardians, and caregivers understand and manage narcolepsy [48, 74, 75]. Some useful behavioral interventions include counseling and cognitive behavioral techniques that use sleep satiation to reduce daytime sleepiness attacks, imagery rehearsal therapy to reduce and manage sleeprelated hallucinations, and systemic desensitization or stimulus control to reduce cataplexy attacks [74, 75]. Patient support and advocacy groups may also be useful to provide those affected with narcolepsy with a feeling of control over their illness and, thus, reduce its negative impact on their lives [76].

Regarding the pharmacologic strategies available, the American Academy of Sleep Medicine (AASM) in 2021 updated its recommendations for narcolepsy treatment because the previous recommendations were published in 2007 [72] and new medications for narcolepsy have since been approved [77].

\section{Pharmacologic Therapy}

Table 4 lists the drugs currently available for narcolepsy, which are targeted primarily at EDS, cataplexy/REM-related symptoms, or both.

\section{Treatments for EDS and Cataplexy}

\section{Oxybates}

Oxybates are the first-line treatment for cataplexy and are available in two formulations [55, 78]: (1) sodium oxybate; and (2) calcium, magnesium, potassium, and low-sodium oxybate $[79,80]$.

In general, sodium oxybate is well tolerated [81]; however, it has a high sodium content, which needs to be considered in patients with sodium-sensitive hypertension, renal dysfunction, or congestive heart failure [82-84]. The lower-sodium formulation has similar effectiveness but contains $92 \%$ less sodium than sodium oxybate [83], which makes it a better option for treating patients who benefit from a low-sodium diet. This formulation was approved by the US Food and Drug Administration (FDA) in 2020 [80]. Both oxybate formulations are approved in the USA for the treatment of cataplexy or EDS in patients with narcolepsy $[79,80]$.

\section{Pitolisant}

Pitolisant is a first-in-class histamine $\mathrm{H}_{3}$ receptor antagonist/inverse agonist [85]. By blocking the inhibitory effect of histamine on histamine release, pitolisant activates histaminergic neurons in the central nervous system, promoting the release of other sleep-wake regulating neurotransmitters, such as norepinephrine, dopamine, serotonin, and acetylcholine $[84,85]$.

In the USA, pitolisant was approved for the treatment of EDS in 2019 and for the treatment of cataplexy in adult patients with narcolepsy in 2020 [86]. However, although it has a beneficial effect on sleep paralysis and sleep-related hallucinations, its effect on nocturnal sleep is less beneficial than that of sodium oxybate $[84,87]$. Pitolisant may reduce the efficacy of oral contraceptives; thus, alternative methods of contraception should be used during treatment and 
Table 4 Currently available treatments for narcolepsy

\begin{tabular}{|c|c|c|c|c|}
\hline Drug & Indication & Mechanism of action & Advantages & Disadvantages \\
\hline Modafinil & $\begin{array}{l}\text { Improve wakefulness in } \\
\text { adults with excessive } \\
\text { sleepiness associated } \\
\text { with narcolepsy, OSA, } \\
\text { or shift-work disorder } \\
\text { [93] }\end{array}$ & $\begin{array}{l}\text { Weak inhibitor of } \\
\text { dopamine reuptake } \\
{[111]}\end{array}$ & $\begin{array}{l}\text { Lower potential for } \\
\text { abuse than some } \\
\text { other stimulants } \\
{[3,111]}\end{array}$ & $\begin{array}{c}\text { Interferes with oral } \\
\text { contraceptives }[3] \\
\text { Drug-induced rash } \\
{[3,76,93]}\end{array}$ \\
\hline Armodafinil & $\begin{array}{l}\text { Improve wakefulness in } \\
\text { adults with excessive } \\
\text { sleepiness associated } \\
\text { with narcolepsy, OSA, } \\
\text { or shift-work disorder } \\
{[112]}\end{array}$ & $\begin{array}{l}\text { Indirect dopamine } \\
\text { receptor agonist [112] }\end{array}$ & $\begin{array}{l}\text { Lower potential for } \\
\text { abuse than some } \\
\text { other stimulants } \\
{[3]}\end{array}$ & $\begin{array}{c}\text { Interferes with oral } \\
\text { contraceptives }[3] \\
\text { Drug-induced rash } \\
{[3,76,112]}\end{array}$ \\
\hline Methylphenidate & $\begin{array}{l}\text { Treatment of ADHD } \\
\text { and EDS in narcolepsy } \\
{[74,113]}\end{array}$ & $\begin{array}{l}\text { Increases dopamine and } \\
\text { norepinephrine } \\
\text { transmission [74] }\end{array}$ & & $\begin{array}{l}\text { Potential for abuse } \\
\text { [113] } \\
\text { AEs (e.g., irritability, } \\
\text { nervousness, heart } \\
\text { rhythm disturbances, } \\
\text { nighttime sleep } \\
\text { disruption) }[113,114]\end{array}$ \\
\hline Amphetamines & $\begin{array}{l}\text { Treatment of EDS in } \\
\text { narcolepsy [3] }\end{array}$ & $\begin{array}{l}\text { Enhanced release of } \\
\text { dopamine and, to a } \\
\text { lesser extent, } \\
\text { norepinephrine from } \\
\text { presynaptic terminals } \\
\text { and inhibition of their } \\
\text { reuptake [55] }\end{array}$ & & $\begin{array}{l}\text { Potential for abuse } \\
{[3,114]} \\
\text { AEs (e.g., irritability, } \\
\text { overstimulation, } \\
\text { shakiness, CV AEs } \\
\text { [such as tachycardia } \\
\text { and hypertension], } \\
\text { nighttime sleep } \\
\text { disruption) }[3,55]\end{array}$ \\
\hline Oxybates & $\begin{array}{l}\text { Treatment of EDS or } \\
\text { cataplexy in patients } \\
\text { with narcolepsy } \\
{[79,80]}\end{array}$ & $\begin{array}{c}\mathrm{GABA}_{\mathrm{B}} \text { receptor agonist } \\
\text { in the CNS [74] }\end{array}$ & $\begin{array}{l}\text { Can be used in } \\
\text { children } \geq 7 \text { years } \\
\text { old }[79,80] \\
\text { A low-sodium } \\
\text { formulation is } \\
\text { available }[80,84]\end{array}$ & $\begin{array}{l}\text { Potential for abuse } \\
\text { Requires twice-nightly } \\
\text { dosing }[3,74] \\
\text { Risk of CNS and } \\
\text { respiratory } \\
\text { suppression; risk of } \\
\text { anxiety and other } \\
\text { psychiatric AEs } \\
{[79,80]}\end{array}$ \\
\hline
\end{tabular}


Table 4 continued

\begin{tabular}{|c|c|c|c|c|}
\hline Drug & Indication & Mechanism of action & Advantages & Disadvantages \\
\hline Pitolisant & $\begin{array}{l}\text { Treatment of EDS or } \\
\text { cataplexy in adults } \\
\text { with narcolepsy [86] }\end{array}$ & $\begin{array}{l}\text { Histamine } \mathrm{H}_{3} \text { receptor } \\
\text { antagonist/inverse } \\
\text { agonist }[85,86]\end{array}$ & $\begin{array}{l}\text { Low rates of } \\
\text { treatment- } \\
\text { emergent AEs [84] }\end{array}$ & $\begin{array}{l}\text { Interferes with oral } \\
\text { contraceptives [86] }\end{array}$ \\
\hline Solriamfetol & $\begin{array}{l}\text { Improve wakefulness in } \\
\text { adults with EDS } \\
\text { associated with } \\
\text { narcolepsy or OSA } \\
\text { [88] }\end{array}$ & $\begin{array}{l}\text { Selective inhibitor of the } \\
\text { reuptake of dopamine } \\
\text { and norepinephrine; } \\
\text { does not promote the } \\
\text { release of monoamines } \\
{[74,76]}\end{array}$ & $\begin{array}{l}\text { Does not interfere } \\
\text { with oral } \\
\text { contraceptives } \\
{[76,84]} \\
\text { May improve } \\
\text { alertness better than } \\
\text { other agents [84] }\end{array}$ & $\begin{array}{l}\text { Increases BP and HR } \\
{[84,88]} \\
\text { May be associated with } \\
\text { psychiatric symptoms } \\
{[88]} \\
\text { Interacts with MAO } \\
\text { inhibitors and } \\
\text { dopaminergic drugs } \\
\text { [88] }\end{array}$ \\
\hline $\begin{array}{l}\text { SNRIs, } \\
\text { venlafaxine }\end{array}$ & $\begin{array}{l}\text { Off-label treatment of } \\
\text { cataplexy in narcolepsy } \\
{[3,74]}\end{array}$ & $\begin{array}{l}\text { Selective norepinephrine } \\
\text { reuptake inhibitor }[84]\end{array}$ & $\begin{array}{l}\text { Fewer AEs than with } \\
\text { TCAs [84] } \\
\text { Available in } \\
\text { extended-release } \\
\text { formulation [115] }\end{array}$ & $\begin{array}{l}\text { AEs (insomnia, mental } \\
\text { stimulation, reduced } \\
\text { sexual function) } \\
{[3,115]} \\
\text { Rebound cataplexy } \\
\text { following withdrawal } \\
{[74]}\end{array}$ \\
\hline
\end{tabular}

$A D H D$ attention-deficit hyperactivity disorder, $A E s$ adverse events, $B P$ blood pressure, $C N S$ central nervous system, $C V$ cardiovascular, $E D S$ excessive daytime sleepiness, $G A B A_{B}$ gamma-hydroxybutyric acid $\mathrm{B}, H R$ heart rate, $M A O$ monoamine oxidase, $O S A$ obstructive sleep apnea, $S N R I s$ selective norepinephrine reuptake inhibitors, $T C A s$ tricyclic antidepressants

for at least 21 days after treatment discontinuation [86].

\section{Treatments for EDS}

\section{Solriamfetol}

Solriamfetol is a phenylalanine derivative that inhibits dopamine and norepinephrine reuptake by interacting with dopamine and norepinephrine transporters [76]. It was first approved in 2019 in the USA for the treatment of EDS in adult patients with narcolepsy or obstructive sleep apnea [88]. Solriamfetol was significantly more effective than placebo in improving wakefulness in patients with narcolepsy in phase 2 and phase 3 clinical trials [89-91]. In addition, one of the advantages of solriamfetol is that, unlike other drugs used to treat daytime sleepiness (such as modafinil, armodafinil, and pitolisant), it has no adverse effects on the efficacy of oral contraceptives [76].

\section{Modafinils (Modafinil, Armodafinil)}

Modafinil and armodafinil are non-amphetamine stimulants of the central nervous system. These two agents have very similar chemical structures; whereas modafinil is the racemic compound, armodafinil is the $(R)$ enantiomer of modafinil. Both agents have the same pharmacologic properties with no difference in their efficacy and safety. They both act as inhibitors of dopamine reuptake, promoting wakefulness and relieving EDS [92]. 
Modafinil is currently only approved for the treatment of EDS in narcolepsy in the USA [93] and has no reported effects on cataplexy. It can be considered a first-line treatment for narcolepsy-associated EDS [94]. However, alternative effective contraceptive options should be provided to women during and after treatment with modafinil as it may affect steroidal contraceptive efficacy as a result of the induction of cytochrome P450 (CYP) 3A4/5 [74, 95].

\section{Other stimulants}

Stimulants, including various formulations of methylphenidate and amphetamines, approved for the treatment of ADHD are used off-label to treat narcolepsy. There are no data from clinical trials to support the correct dosing in narcolepsy [37]. Currently, methylphenidate is regarded as a second-line drug for EDS and amphetamines are regarded as third-line drugs for EDS [74]. These drugs enhance dopaminergic and noradrenergic neurotransmission, thereby improving subjective concentration; however, they may be less effective than modafinil in promoting wakefulness [96]. Moreover, cardiovascular and mental stimulation, as well as abuse potential, limit the use of amphetamines and methylphenidate for treating EDS $[3,55]$.

\section{Treatments for Cataplexy}

Aside from pitolisant and the oxybates, no agents are approved by the FDA for the treatment of narcolepsy-associated cataplexy. However, some classes of antidepressants are used off-label, specifically the selective serotonin reuptake inhibitors (SSRIs) and selective norepinephrine reuptake inhibitors (SNRIs) [97].

\section{Emerging Treatments}

Emerging treatments for narcolepsy include FT218 , which is a controlled-release, once-nightly formulation of sodium oxybate for EDS and cataplexy $[98,99]$. This drug has been investigated in a double-blind, randomized, placebocontrolled, two-arm, multicenter study to assess its efficacy and safety (NCT02720744) [98], and is currently before the FDA for approval [99]. TAK-925 is an orexin-2-receptor-selective agonist being developed for the treatment of fragmented wakefulness and cataplexy. This drug has been studied in a phase $1 \mathrm{~b}$ clinical trial in sleep-deprived healthy adults and in patients with narcolepsy (NCT03332784) [100, 101]. Another orexin-2-receptor-selective agonist, TAK-994, is currently being investigated in a phase 2 clinical trial for adults with NT1 and NT2 (NCT04096560) [102, 103]. AXS-12 (reboxetine), a norepinephrine reuptake inhibitor, is currently being investigated in a phase 3 clinical trial for the treatment of cataplexy in adults with narcolepsy (trial initiation anticipated in Q3 2021) [104, 105]. SUVN-G3031, which is a histamine $\mathrm{H}_{3}$ receptor inverse agonist [105], is also being evaluated for the treatment of adults with narcolepsy with and without catalepsy in a phase 2 , double-blind, placebocontrolled, parallel-group, multicenter study (NCT04072380) [106].

\section{TREATMENT DECISIONS}

To achieve treatment success and improve patients' quality of life, it is important to include the patients in treatment decisions [3]. This would help physicians to treat the predominant symptoms of narcolepsy (e.g., EDS, cataplexy) as well as the symptoms that are of most concern to patients [3]. In addition to the clinical details of each individual patient, their work schedule, caregiving responsibilities, lifestyle, and past and current medication prescriptions should be considered when choosing the treatment for each patient, as shown in Fig. $2[3,82]$. The patient's concomitant medications should be reviewed for agents that may exacerbate the symptoms of narcolepsy or disrupt the delicate balance between wakefulness and sleepiness (e.g., gabapentin, opioids, alpha1 agonists) [3, 82]. Also, modafinil, armodafinil, and pitolisant may interact with oral contraceptives, so women using these agents for birth control may need to consider an alternative contraceptive method [3, 86]. Figure 2 shows treatment considerations that can assist in decision-making in patients with narcolepsy. 


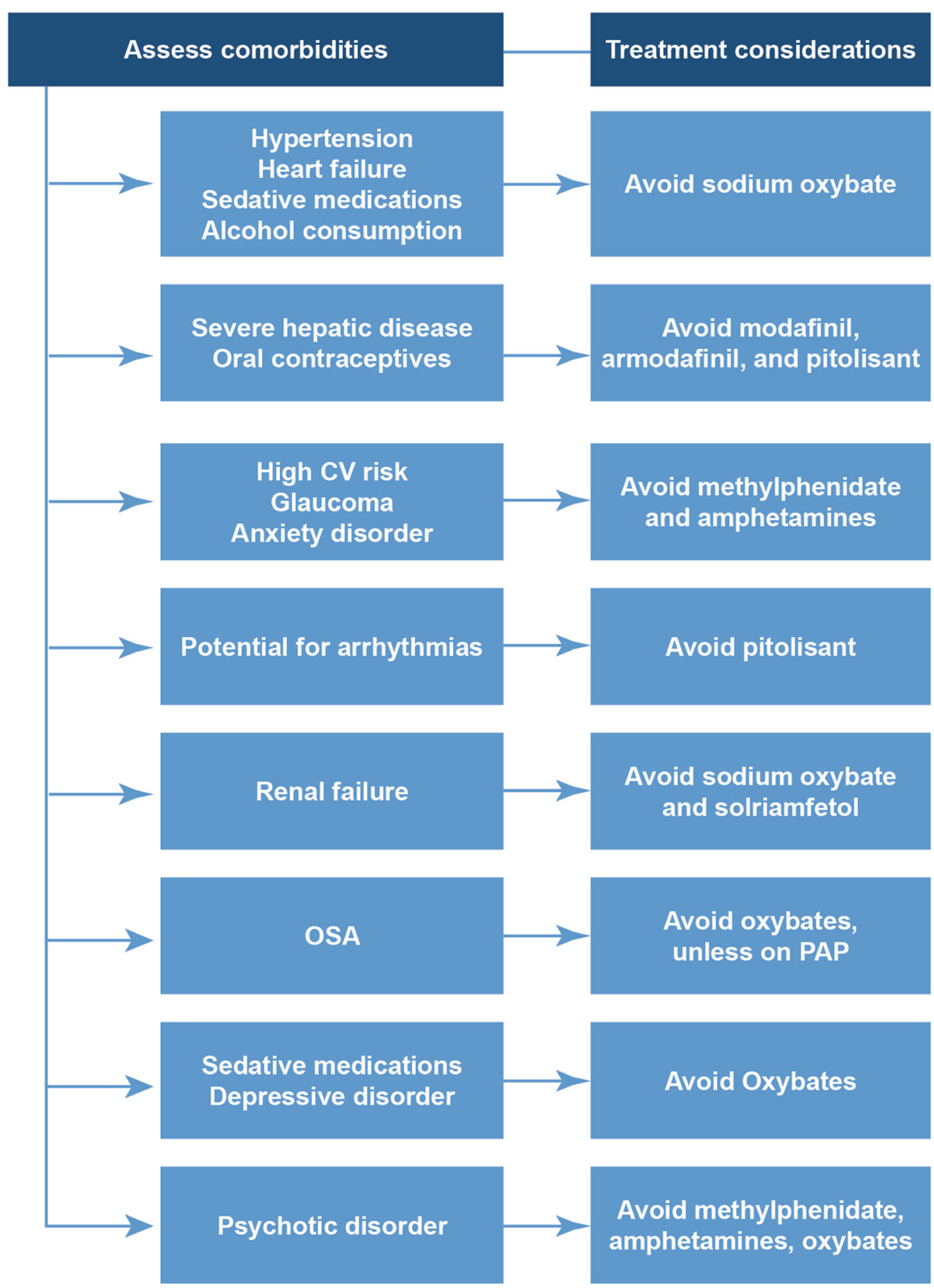

Fig. 2 Comorbidities to be considered when prescribing medications for narcolepsy. CV cardiovascular, OSA obstructive sleep apnea, PAP positive airway pressure

Patient age is an important consideration in choosing a treatment. Sodium oxybate is the only anticataplectic medication with an approved indication for pediatric narcolepsy (children aged $\geq 7$ years) $[79,80]$; some of the methylphenidate and amphetamine stimulants 
approved for ADHD are also approved for narcolepsy [3] and, therefore, may be used in children with EDS as the predominant symptom $[3,107]$. On the other hand, sodium oxybate may not be suitable for adults who need to be alert at night, such as those on-call at night or those with caregiving responsibilities for young children or elderly relatives [3]. Patients who consume alcohol are not candidates for sodium oxybate because of increased risk of respiratory depression.

Older patients may have renal or hepatic dysfunction that affects the clearance of some drugs, increasing the risk of adverse events [108]. For example, solriamfetol is largely excreted in the urine, whereas pitolisant is mainly metabolized by the cytochrome P450 system in the liver $[84,109]$. Sodium oxybate has a large salt content, which may adversely affect those with renal dysfunction [3, 84].

Comorbidities, which are common in older patients, may also affect drug choice (Fig. 2) $[3,82]$. As described earlier, orexin deficiency blunts the usual drop in blood pressure and heart rate that occurs during sleep [30], which may place vulnerable individuals at an increased risk of cardiovascular events [3]. Careful cardiovascular risk assessment is advisable, particularly in older patients or obese individuals who may have hypertension, diabetes, hyperlipidemia, or other cardiovascular risk factors $[3,82]$. Pitolisant may prolong the QT interval, placing patients at an increased risk of arrhythmia, so it should be avoided in combination with other agents that prolong the QT interval [86]. The high sodium content of sodium oxybate needs to be considered in patients with cardiovascular conditions, such as salt-sensitive hypertension or congestive heart failure [82]; it may be advisable to use the lowersodium formulation in these patients [84]. Methylphenidate and amphetamines are contraindicated in patients with high cardiovascular risk or glaucoma [3, 82].

Cognitive impairment can be magnified in older patients with narcolepsy, so effective treatment in this age group is important for both symptomatic relief and for ameliorating the psychosocial impact of cognitive dysfunction. Profoundly sedating treatments, such as oxybates, may increase the risk of falls in older patients with nocturnal wandering or nocturia $[82,110]$.

\section{CONCLUSIONS}

Narcolepsy is a frequently under-recognized chronic disorder associated with significant burden in the form of reduced quality of life and productivity, as well as increased healthcare resource utilization and costs. The discovery of the loss of orexin neurons in CSF has paved the way for a greater understanding of narcolepsy and for the development of targeted therapies. However, improvements in the recognition and management of narcolepsy, especially in those without cataplexy, are needed to reduce the substantial burden on affected individuals. Physicians should be alert to the possibility of a narcolepsy diagnosis in all patients with persistent EDS, especially if it is associated with signs of REM disruption (such as cataplexy or sleeprelated hallucinations), and refer patients to a center for sleep medicine for confirmation of the diagnosis. Treatment decisions should take into account a patient's complete clinical and psychosocial situation, particularly the symptoms that are most bothersome to the patient and importantly the comorbidities that may affect treatment choices.

\section{ACKNOWLEDGEMENTS}

Funding. The funding for this manuscript and the Rapid Service and Open Access Fees were provided by Jazz Pharmaceuticals, Palo Alto, CA, USA.

Medical Writing and Editorial Assistance. Catherine Rees and Alma Orts-Sebastian of inscience Communications, Springer Healthcare (New York, NY, USA), Elizabeth Samander of Springer Healthcare (New York, NY, USA) and Michael Coco, PhD, of Coco Communications Inc. (Atlanta, GA) provided medical writing support and Brad Zerlanko of Springer Healthcare (Jersey City, NJ, USA) 
provided editorial support. This assistance was funded by an unrestricted medical education grant from Jazz Pharmaceuticals (Palo Alto, CA, USA).

Authorship. All named authors meet the International Committee of Medical Journal Editors (ICMJE) criteria for authorship for this article, take responsibility for the integrity of the work as a whole, and have given their approval for this version to be published.

Authors' Contributions. Phyllis C. Zee, Michael J. Thorpy, and Lois E. Krahn contributed to the manuscript conception and design and participated in the draft manuscript preparation and revision. All authors read and approved the final manuscript.

Disclosures. Lois E. Krahn has received research funding from Avadel Pharmaceuticals, Balance Therapeutics, Harmony Biosciences, Jazz Pharmaceuticals, Suven Life Sciences, and Takeda. Phyllis C. Zee serves as a consultant and/or advisor for Jazz Pharmaceuticals, Harmony Biosciences, and Eisai Pharmaceuticals, and served as a consultant/advisor for CVS/ Caremark in 2019 and 2020. Dr Zee has equity ownership/stock options in Teva Pharmaceuticals and received lecture fees/honoraria from Eisai Pharmaceuticals in 2020. Michael J. Thorpy serves as a consultant/advisor for Axsome, Balance Therapeutics, Eisai Pharmaceuticals, Harmony Biosciences, Jazz Pharmaceuticals, NLS Pharmaceuticals, Suven Life Sciences, Takeda, and XW Pharma.

Compliance with Ethics Guidelines. This article is based on previously conducted studies and does not contain any new studies with human participants or animals performed by any of the authors.

Data Availability. Data sharing is not applicable to this article as no datasets were generated or analyzed during the current study.

Open Access. This article is licensed under a Creative Commons Attribution-NonCommercial 4.0 International License, which permits any non-commercial use, sharing, adaptation, distribution and reproduction in any medium or format, as long as you give appropriate credit to the original author(s) and the source, provide a link to the Creative Commons licence, and indicate if changes were made. The images or other third party material in this article are included in the article's Creative Commons licence, unless indicated otherwise in a credit line to the material. If material is not included in the article's Creative Commons licence and your intended use is not permitted by statutory regulation or exceeds the permitted use, you will need to obtain permission directly from the copyright holder. To view a copy of this licence, visit http://creativecommons.org/licenses/by$\mathrm{nc} / 4.0 /$.

\section{REFERENCES}

1. Harris SF, Monderer RS, Thorpy M. Hypersomnias of central origin. Neurol Clin. 2012;30:1027-44.

2. Sateia MJ. International classification of sleep disorders-third edition: highlights and modifications. Chest. 2014;146:1387-94.

3. Thorpy MJ, Dauvilliers Y. Clinical and practical considerations in the pharmacologic management of narcolepsy. Sleep Med. 2015;16:9-18.

4. Scammell TE. Narcolepsy. N Engl J Med. 2015;373: 2654-62.

5. Kornum BR, Knudsen S, Ollila HM, et al. Narcolepsy. Nat Rev Dis Primers. 2017;3:16100.

6. Thorpy MJ, Krieger AC. Delayed diagnosis of narcolepsy: characterization and impact. Sleep Med. 2014;15:502-7.

7. Ruoff CM, Reaven NL, Funk SE, et al. High rates of psychiatric comorbidity in narcolepsy: findings from the Burden of Narcolepsy Disease (BOND) study of 9,312 patients in the United States. J Clin Psychiatry. 2017;78:171-6.

8. Maski K, Steinhart E, Williams D, et al. Listening to the patient voice in narcolepsy: diagnostic delay, disease burden, and treatment efficacy. J Clin Sleep Med. 2017;13:419-25. 
9. Plazzi G, Clawges HM, Owens JA. Clinical characteristics and burden of illness in pediatric patients with narcolepsy. Pediatr Neurol. 2018;85:21-32.

10. Black J, Reaven NL, Funk SE, et al. The Burden of Narcolepsy Disease (BOND) study: health-care utilization and cost findings. Sleep Med. 2014;15: 522-9.

11. Flores NM, Villa KF, Black J, Chervin RD, Witt EA. The humanistic and economic burden of narcolepsy. J Clin Sleep Med. 2016;12:401-7.

12. American Psychiatric Association. Sleep-wake disorders. In: Diagnostic and Statistical Manual of Mental Disorders, 5th edn. Washington, DC: American Psychiatric Association; 2013. p. 361-422.

13. Ruoff C, Rye D. The ICSD-3 and DSM-5 guidelines for diagnosing narcolepsy: clinical relevance and practicality. Curr Med Res Opin. 2016;32:1611-22.

14. Baumann CR, Mignot E, Lammers GJ, et al. Challenges in diagnosing narcolepsy without cataplexy: a consensus statement. Sleep. 2014;37:1035-42.

15. Trotti LM. Waking up is the hardest thing I do all day: sleep inertia and sleep drunkenness. Sleep Med Rev. 2017;35:76-84.

16. Bagai K, Malow BA. A novel approach to treating morning sleep inertia in narcolepsy. J Clin Sleep Med. 2010;6:77-8.

17. Roth T, Dauvilliers Y, Mignot E, et al. Disrupted nighttime sleep in narcolepsy. J Clin Sleep Med. 2013;9:955-65.

18. Seifinejad A, Li S, Possovre ML, Vassalli A, Tafti M. Hypocretinergic interactions with the serotonergic system regulate REM sleep and cataplexy. Nat Commun. 2020;11:6034.

19. Antelmi E, Pizza F, Vandi S, et al. The spectrum of REM sleep-related episodes in children with type 1 narcolepsy. Brain. 2017;140:1669-79.

20. Thorpy MJ. Diagnostic criteria and delay in diagnosis of narcolepsy. In: Goswami M, Thorpy MJ, Pandi-Perumal SR, editors. Narcolepsy: a clinical guide. 2nd ed. Cham: Springer; 2016. p. 45-9.

21. Ahmed I, Thorpy M. Clinical features, diagnosis and treatment of narcolepsy. Clin Chest Med. 2010;31: 371-81.

22. Black J, Reaven NL, Funk SE, et al. Medical comorbidity in narcolepsy: findings from the Burden of Narcolepsy Disease (BOND) study. Sleep Med. 2017;33:13-8.
23. Longstreth WT Jr, Koepsell TD, Ton TG, Hendrickson AF, van Belle G. The epidemiology of narcolepsy. Sleep. 2007;30:13-26.

24. Mahoney CE, Cogswell A, Koralnik IJ, Scammell TE. The neurobiological basis of narcolepsy. Nat Rev Neurosci. 2019;20:83-93.

25. Liblau RS, Vassalli A, Seifinejad A, Tafti M. Hypocretin (orexin) biology and the pathophysiology of narcolepsy with cataplexy. Lancet Neurol. $2015 ; 14: 318-28$

26. Branch AF, Navidi W, Tabuchi S, et al. Progressive loss of the orexin neurons reveals dual effects on wakefulness. Sleep. 2016;39:369-77.

27. Mieda M. The roles of orexins in sleep/wake regulation. Neurosci Res. 2017;118:56-65.

28. Pedersen NW, Holm A, Kristensen NP, et al. CD8(+) $\mathrm{T}$ cells from patients with narcolepsy and healthy controls recognize hypocretin neuron-specific antigens. Nat Commun. 2019;10:837.

29. Wasserman D, Bassetti CLA, Rosenzweig I. Narcolepsy with resolution of cataplexy and persisting orexin deficiency. J Clin Sleep Med. 2020;16: 1383-6.

30. Berteotti C, Silvani A. The link between narcolepsy and autonomic cardiovascular dysfunction: a translational perspective. Clin Auton Res. 2018;28: 545-55.

31. Taheri S. The genetics of narcolepsy. In: Goswami M, Thorpy MJ, Pandi-Perumal SR, editors. Narcolepsy: a clinical guide. 2nd ed. Springer: Cham; 2016. p. 3-10.

32. Tafti M, Hor H, Dauvilliers Y, et al. DQB1 locus alone explains most of the risk and protection in narcolepsy with cataplexy in Europe. Sleep. 2014;37:19-25.

33. Hallmayer J, Faraco J, Lin L, et al. Narcolepsy is strongly associated with the T-cell receptor alpha locus. Nat Genet. 2009;41:708-11.

34. De la Herrán-Arita AK, García-García F. Narcolepsy as an immune-mediated disease. Sleep Disord. 2014;2014:792687. https://doi.org/10.1155/2014/ 792687.

35. Mahlios J, De la Herrán-Arita AK, Mignot E. The autoimmune basis of narcolepsy. Curr Opin Neurobiol. 2013;23:767-73.

36. Hartmann FJ, Bernard-Valnet R, Queriault C, et al. High-dimensional single-cell analysis reveals the immune signature of narcolepsy. J Exp Med. 2016;213:2621-33. 
37. Latorre D, Kallweit U, Armentani E, et al. T cells in patients with narcolepsy target self-antigens of hypocretin neurons. Nature. 2018;562:63-8.

38. Kornum BR, Burgdorf KS, Holm A, Ullum H, Jennum $\mathrm{P}$, Knudsen S. Absence of autoreactive CD4(+) T-cells targeting HLA-DQA1*01:02/DQB1*06:02 restricted hypocretin/orexin epitopes in narcolepsy type 1 when detected by EliSpot. J Neuroimmunol. 2017;309:7-11.

39. Luo G, Ambati A, Lin L, et al. Autoimmunity to hypocretin and molecular mimicry to flu in type 1 narcolepsy. Proc Natl Acad Sci U S A. 2018;115: E12323-32.

40. Aran A, Lin L, Nevsimalova S, et al. Elevated antistreptococcal antibodies in patients with recent narcolepsy onset. Sleep. 2009;32:979-83.

41. Han F, Lin L, Warby SC, et al. Narcolepsy onset is seasonal and increased following the 2009 H1N1 pandemic in China. Ann Neurol. 2011;70:410-7.

42. Miyagawa T, Tokunaga K. Genetics of narcolepsy. Hum Genome Var. 2019;6:4.

43. Faraco J, Lin L, Kornum BR, et al. ImmunoChip study implicates antigen presentation to T cells in narcolepsy. PLoS Genet. 2013;9:e1003270.

44. Holm A, Lin L, Faraco J, et al. EIF3G is associated with narcolepsy across ethnicities. Eur J Hum Genet. 2015;23:1573-80.

45. Morse AM, Sanjeev K. Narcolepsy and psychiatric disorders: comorbidities or shared pathophysiology? Med Sci (Basel). 2018;6:16.

46. Bassetti CL, Adamantidis A, Burdakov D, et al. Narcolepsy-clinical spectrum, aetiopathophysiology, diagnosis and treatment. Nat Rev Neurol. 2019;15:519-39.

47. American Academy of Sleep Medicine. International classification of sleep disorders. 3rd ed. Darien, IL: American Academy of Sleep Medicine; 2014.

48. Morse AM. Narcolepsy in children and adults: a guide to improved recognition, diagnosis and management. Med Sci (Basel). 2019;7:106.

49. Filardi M, Pizza F, Bruni O, Natale V, Plazzi G. Circadian rest-activity rhythm in pediatric type 1 narcolepsy. Sleep. 2016;39:1241-7.

50. Filardi M, Pizza F, Martoni M, Vandi S, Plazzi G, Natale V. Actigraphic assessment of sleep/wake behavior in central disorders of hypersomnolence. Sleep Med. 2015;16:126-30.
51. Torstensen EW, Pickering L, Kornum BR, Wanscher B, Baandrup L, Jennum PJ. Diagnostic value of actigraphy in hypersomnolence disorders. Sleep Med. 2021;85:1-7.

52. Benmedjahed K, Wang YG, Lambert J, et al. Assessing sleepiness and cataplexy in children and adolescents with narcolepsy: a review of current patient-reported measures. Sleep Med. 2017;32: 143-9.

53. Kallweit U, Schmidt M, Bassetti CL. Patient-reported measures of narcolepsy: the need for better assessment. J Clin Sleep Med. 2017;13:737-44.

54. Wang YG, Benmedjahed K, Lambert J, et al. Assessing narcolepsy with cataplexy in children and adolescents: development of a cataplexy diary and the ESS-CHAD. Nat Sci Sleep. 2017;9:201-11.

55. Barateau L, Lopez R, Dauvilliers Y. Treatment options for narcolepsy. CNS Drugs. 2016;30:369-79.

56. Filardi M, D'Anselmo A, Agnoli S, et al. Cognitive dysfunction in central disorders of hypersomnolence: a systematic review. Sleep Med Rev. 2021;59: 101510.

57. Filardi M, Pizza F, Tonetti L, Antelmi E, Natale V, Plazzi G. Attention impairments and ADHD symptoms in adult narcoleptic patients with and without hypocretin deficiency. PLoS ONE. 2017;12: e0182085.

58. Schneider C, Fulda S, Schulz H. Daytime variation in performance and tiredness/sleepiness ratings in patients with insomnia, narcolepsy, sleep apnea and normal controls. J Sleep Res. 2004;13:373-83.

59. Thomann J, Baumann CR, Landolt HP, Werth E. Psychomotor vigilance task demonstrates impaired vigilance in disorders with excessive daytime sleepiness. J Clin Sleep Med. 2014;10:1019-24.

60. Maness C, Saini P, Bliwise DL, Olvera V, Rye D, Trotti LM. Systemic exertion intolerance disease/ chronic fatigue syndrome is common in sleep center patients with hypersomnolence: a retrospective pilot study. J Sleep Res. 2019;28:e12689.

61. Bassetti CL, Kallweit U, Vignatelli L, et al. European guideline and expert statements on the management of narcolepsy in adults and children. J Sleep Res. 2021;e13387. https://doi.org/10.1111/jsr. 13387.

62. Carls G, Reddy SR, Broder MS, et al. Burden of disease in pediatric narcolepsy: a claims-based analysis of health care utilization, costs, and comorbidities. Sleep Med. 2020;66:110-8. 
63. Nallu S. Narcolepsy differential diagnoses. In: Benbadis SR, editor. Medscape: Drugs \& Diseases. WebMD. https://emedicine.medscape.com/article/ 1188433-differential. Updated August 3, 2020. Accessed 28 July 2021.

64. Ebben MR, Krieger AC. Narcolepsy with cataplexy masked by the use of nicotine. J Clin Sleep Med. 2012;8:195-6.

65. Weiß D, Kluge M. Waiting 40 years for the correct diagnosis: a complex case of comorbid narcolepsy and ADHD. Aust N Z J Psychiatry. 2020;54:439-40.

66. Cohen A, Mandrekar J, St Louis EK, Silber MH, Kotagal S. Comorbidities in a community sample of narcolepsy. Sleep Med. 2018;43:14-8.

67. Li X, Sanford LD, Zong Q, et al. Prevalence of depression or depressive symptoms in patients with narcolepsy: a systematic review and meta-analysis. Neuropsychol Rev. 2021;31:89-102.

68. Silvani A, Grimaldi D, Barletta G, et al. Cardiovascular variability as a function of sleep-wake behaviour in narcolepsy with cataplexy. J Sleep Res. 2013;22:178-84.

69. Milbank E, López M. Orexins/hypocretins: key regulators of energy homeostasis. Front Endocrinol (Lausanne). 2019;10:830.

70. Mohammadi S, Moosaie F, Saghazadeh A, Mahmoudi M, Rezaei N. Metabolic profile in patients with narcolepsy: a systematic review and metaanalysis. Sleep Med. 2021;81:268-84.

71. Straat ME, Schinkelshoek MS, Fronczek R, Lammers GJ, Rensen PC, Boon MR. Role of brown adipose tissue in adiposity associated with narcolepsy type 1. Front Endocrinol (Lausanne). 2020;11:145.

72. Morgenthaler TI, Kapur VK, Brown T, et al. Practice parameters for the treatment of narcolepsy and other hypersomnias of central origin. Sleep. 2007;30:1705-11.

73. Golden EC, Lipford MC. Narcolepsy: diagnosis and management. Cleve Clin J Med. 2018;85:959-69.

74. Franceschini C, Pizza F, Antelmi E, Folli MC, Plazzi G. Narcolepsy treatment: pharmacological and behavioral strategies in adults and children. Sleep Breath. 2020;24:615-27.

75. Agudelo HA, Correa UJ, Sierra JC, Pandi-Perumal SR, Schenck $\mathrm{CH}$. Cognitive behavioral treatment for narcolepsy: can it complement pharmacotherapy? Sleep Sci. 2014;7:30-42.

76. Barker EC, Flygare J, Paruthi S, Sharkey KM. Living with narcolepsy: current management strategies, future prospects, and overlooked real-life concerns. Nat Sci Sleep. 2020;12:453-66.

77. Maski K, Trotti LM, Kotagal S, et al. Treatment of central disorders of hypersomnolence: an American Academy of Sleep Medicine clinical practice guideline. J Clin Sleep Med. 2021;15:10. https://doi.org/ $10.5664 /$ jcsm.9328.

78. Billiard M, Bassetti C, Dauvilliers Y, et al. EFNS guidelines on management of narcolepsy. Eur J Neurol. 2006;13:1035-48.

79. XYREM ${ }^{\circledR}$ (sodium oxybate) [prescribing information]. Palo Alto, CA: Jazz Pharmaceuticals, Inc.; 2020.

80. XYWAV ${ }^{\mathrm{TM}}$ (calcium, magnesium, potassium, and sodium oxybates) [prescribing information]. Palo Alto, CA: Jazz Pharmaceuticals, Inc.; 2021.

81. Alshaikh MK, Tricco AC, Tashkandi M, Mamdani M, Straus SE, BaHammam AS. Sodium oxybate for narcolepsy with cataplexy: systematic review and meta-analysis. J Clin Sleep Med. 2012;8:451-8.

82. Cornay-Manalo N, Attarian H. Narcolepsy in the older adult. In: Goswami M, Thorpy MJ, PandiPerumal SR, editors. Narcolepsy: a clinical guide. 2nd ed. Cham: Springer; 2016. p. 69-80.

83. Bogan RK, Thorpy MJ, Dauvilliers Y, et al. Efficacy and safety of calcium, magnesium, potassium, and sodium oxybates (lower-sodium oxybate [LXB]; JZP258) in a placebo-controlled, double-blind, randomized withdrawal study in adults with narcolepsy with cataplexy. Sleep. 2020. https://doi.org/ 10.1093/sleep/zsaa206.

84. Thorpy MJ. Recently approved and upcoming treatments for narcolepsy. CNS Drugs. 2020;34: 9-27.

85. Romigi A, Vitrani G, Lo Giudice T, Centonze D, Franco V. Profile of pitolisant in the management of narcolepsy: design, development, and place in therapy. Drug Des Devel Ther. 2018;12:2665-75.

86. WAKIX ${ }^{\circledR} \quad$ (pitolisant) [prescribing information]. Plymouth Meeting, PA: Harmony Biosciences, LLC; 2021.

87. Abad VC. An evaluation of sodium oxybate as a treatment option for narcolepsy. Expert Opin Pharmacother. 2019;20:1189-99.

88. SUNOSI ${ }^{\mathrm{TM}}$ (solriamfetol) [prescribing information]. Palo Alto, CA: Jazz Pharmaceuticals, Inc.; 2019.

89. Bogan RK, Feldman N, Emsellem HA, et al. Effect of oral JZP-110 (ADX-N05) treatment on wakefulness 
and sleepiness in adults with narcolepsy. Sleep Med. 2015;16:1102-8.

90. Schweitzer PK, Rosenberg R, Zammit GK, et al. Solriamfetol for excessive sleepiness in obstructive sleep apnea (TONES 3). A randomized controlled trial. Am J Respir Crit Care Med. 2019;199:1421-31.

91. Thorpy MJ, Shapiro C, Mayer G, et al. A randomized study of solriamfetol for excessive sleepiness in narcolepsy. Ann Neurol. 2019;85:359-70.

92. Lehert P, Falissard B. Multiple treatment comparison in narcolepsy: a network meta-analysis. Sleep. 2018;41:1-13. https://doi.org/10.1093/sleep/ zsy185.

93. PROVIGIL ${ }^{\circledR}$ (modafinil) [prescribing information]. North Wales, PA: Teva Pharmaceuticals USA, Inc.; 2015.

94. Greenblatt K, Adams N. Modafinil. NCBI Bookshelf. Treasure Island: StatPearls Publishing; January 2020. https://www.ncbi.nlm.nih.gov/books/NBK531476/. Updated September 11, 2020. Accessed 29 July 2021.

95. Davies M, Wilton L, Shakir S. Safety profile of modafinil across a range of prescribing indications, including off-label use, in a primary care setting in England. Drug Saf. 2013;36:237-46.

96. Dolder PC, Müller F, Schmid Y, Borgwardt SJ, Liechti ME. Direct comparison of the acute subjective, emotional, autonomic, and endocrine effects of MDMA, methylphenidate, and modafinil in healthy subjects. Psychopharmacology. 2018;235: 467-79.

97. Dauvilliers Y, Siegel JM, Lopez R, Torontali ZA, Peever JH. Cataplexy-clinical aspects, pathophysiology and management strategy. Nat Rev Neurol. 2014;10:386.

98. NCT02720744. Once-nightly sodium oxybate for treatment of excessive daytime sleepiness and cataplexy in narcolepsy. https://clinicaltrials.gov/ct2/ show/NCT02720744. Updated April 3, 2020. Accessed 29 July 2021.

99. Avadel Pharmaceuticals. Avadel Pharmaceuticals announces FDA acceptance of new drug application for FT218 in adults with narcolepsy for the treatment of excessive daytime sleepiness and cataplexy. Intrado GlobalNewswire website. https://www. globenewswire.com/news-release/2021/03/01/ 2184208/0/en/Avadel-Pharmaceuticals-AnnouncesFDA-Acceptance-of-New-Drug-Application-forFT218-in-Adults-with-Narcolepsy-for-theTreatment-of-Excessive-Daytime-Sleepiness-andCataplexy.html. Published March 1, 2021. Accessed 12 Aug 2021.
100. Takeda Pharmaceuticals Protocol. A phase 1b, 4-period crossover, placebo-controlled, randomized, single dose study to evaluate the safety, tolerability, pharmacokinetics, and pharmacodynamics of TAK-925 in sleep-deprived healthy adults utilizing modafinil as an active comparator. https:// clinicaltrials.gov/ProvidedDocs/06/NCT03522506/ Prot_000.pdf. Protocol approved May 8, 2018. Accessed 29 July 2021.

101. NCT03332784. Phase 1 TAK-925 study in healthy adult and elderly volunteers and participants with narcolepsy. https://clinicaltrials.gov/ct2/show/ NCT03332784. Updated March 30, 2021. Accessed 12 Aug 2021.

102. NCT04096560. A study of TAK-994 in adults with type 1 and type 2 narcolepsy. https://clinicaltrials. gov/ct2/show/NCT04096560. Updated August 4, 2021. Accessed 12 Aug 2021.

103. Takeda. US Food and Drug Administration grants breakthrough therapy designation to Takeda's investigational compound, TAK-994, an oral orexin agonist in clinical development for narcolepsy type 1 (NT1). https://www.takeda.com/newsroom/ newsreleases/2021/us-food-and-drugadministration-grants-breakthrough-therapydesignation-to-takedas-investigational-compoundtak-994/. Published July 28, 2021. Accessed 12 Aug 2021.

104. Adis Insight. Reboxetine-Axsome Therapeutics. https://adisinsight.springer.com/drugs/800053169. Updated March 26, 2021. Accessed 12 Aug 2021.

105. Axsome Therapeutics. Axsome Therapeutics announces expedited development of AXS-12 for the treatment of narcolepsy based on FDA breakthrough therapy meeting. Intrado GlobalNewswire website. https://www.globenewswire.com/en/newsrelease/2020/09/21/2096384/33090/en/AxsomeTherapeutics-Announces-Expedited-Developmentof-AXS-12-for-the-Treatment-of-Narcolepsy-Basedon-FDA-Breakthrough-Therapy-Meeting.html. Published September 21, 2020. Accessed 12 Aug 2021.

106. NCT04072380. A study to evaluate safety, and efficacy of SUVN-G3031 in patients with narcolepsy with and without cataplexy (SUVN-G3031). https:// clinicaltrials.gov/ct2/show/NCT04072380. Updated April 12, 2021. Accessed 29 July 2021.

107. Maski K, Owens JA. Insomnia, parasomnias, and narcolepsy in children: clinical features, diagnosis, and management. Lancet Neurol. 2016;15:1170-81.

108. Ruscin JM, Linnebur SA. Pharmacokinetics in older adults. Merck Manual Professional Version. https:// www.merckmanuals.com/professional/geriatrics/ drug-therapy-in-older-adults/pharmacokinetics-in- 
older-adults. Updated July 2021. Accessed 20 Aug 2021.

109. Abad VC. Profile of solriamfetol in the management of excessive daytime sleepiness associated with narcolepsy or obstructive sleep apnea: focus on patient selection and perspectives. Nat Sci Sleep. 2021;13:75-91.

110. Narcolepsy fact sheet. National Institute of Neurological Disorders and Stroke website. https://www. ninds.nih.gov/Disorders/Patient-CaregiverEducation/Fact-Sheets/Narcolepsy-Fact-Sheet. Updated September 30, 2020. Accessed 20 Aug 2021.

111. Wisor J. Modafinil as a catecholaminergic agent: empirical evidence and unanswered questions.
Front Neurol. 2013. https://doi.org/10.3389/fneur. 2013.00139.

112. NUVIGIL ${ }^{\circledR}$ (armodafinil) [prescribing information]. North Wales, PA: Teva Pharmaceuticals USA, Inc. ;2018.

113. RITALIN ${ }^{\circledR}$ (methylphenidate hydrochloride) [prescribing information]. East Hanover, NJ: Novartis Pharmaceuticals Corporation; 2019.

114. Kallweit U, Bassetti CL. Pharmacological management of narcolepsy with and without cataplexy. Expert Opin Pharmacother. 2017;18:809-17.

115. EFFEXOR XR ${ }^{\circledR}$ (venlafaxine Extended-Release) [prescribing information]. Philadelphia, PA: Wyeth Pharmaceuticals LLC; 2021. 